\title{
Tropical cyclone climatology and variability in Taiwan and Philippine Region during 1979 - 2018
}

\author{
Mong-Ming Lu ${ }^{1, *}$, Chung-Hsiung Sui ${ }^{1}$, Ching-Hsuan $\mathrm{Wu}^{1}$, Ana Liza Solmoro Solis ${ }^{2}$, and \\ Ming-Dean Cheng ${ }^{3}$ \\ ${ }^{1}$ Department of Atmospheric Sciences, National Taiwan University, Taipei City, Taiwan \\ ${ }^{2}$ Philippine Atmospheric Geophysical and Astronomical Services Administration, Metro Manila, Philippines \\ ${ }^{3}$ Central Weather Bureau, Taipei City, Taiwan
}

\begin{abstract}
Article history:
Received 23 June 2020

Revised 14 October 2020

Accepted 30 November 2020

Keywords:

Tropical cyclone, Taiwan and Philippine climate, Indo-Pacific climate variability

\section{Citation:}

Lu, M.-M., C.-H. Sui, C.-H. Wu, A. L. S. Solis, and M.-D. Cheng, 2021: Tropical cyclone climatology and variability in Taiwan and Philippine Region during 1979 - 2018. Terr. Atmos. Ocean. Sci., 32, 725-740, doi: 10.3319/TAO.2020.11.30.01
\end{abstract}

\begin{abstract}
Taiwan and Philippine (TWPH) $\left(117-129^{\circ} \mathrm{E}, 5-26^{\circ} \mathrm{N}\right)$ is a region with most frequent and intense tropical cyclone (TC) influence in the world. This paper documents the climatology and variability of TWPH TC activity with specific attention to the difference in the TCs formed over the western North Pacific (WNP) and over the South China Sea (SCS). The spatial characteristics of TWPH TCs are analyzed based on the accumulated cyclone kinetic energy (ACE) in four sub-areas where distinctly different TC seasonality and variability is found. Different from over the broad Northwest Pacific Basin $\left(0-60^{\circ} \mathrm{N}, 100^{\circ} \mathrm{E}-180^{\circ}\right)$ where the WNP-born TC frequency dropped sharply in late-1990s and the SCS-born TC frequency slightly increased in mid-1990s, over TWPH three distinct epochs are identified. A weakvariability epoch occurred during 1979 - 1996, a persistent low-ACE epoch during 1997 - 2002, and a more variable epoch during 2003 - 2018. The second epoch is most noteworthy. The unusually weak TC activity during this period in particular over the Philippines was associated with anomalously strong anticyclone over the SCS and the Philippine Sea during the East Asian summer monsoon season. The strong anticyclonic circulation appeared as a descending leg of the enhanced East Asian summer monsoon during summer (July to September). During autumn and early winter (September to December) the Philippine Sea anticyclone was interpreted as the descending Rossby wave response to the suppressed convection over tropical western Pacific. The anomalous anticyclone strengthened the low-level confluent flow and convection over the SCS. The findings are useful to real-time TWPH TC activity monitoring and analysis.
\end{abstract}

\section{INTRODUCTION}

Taiwan and the Philippines are densely populated territories with more than 125 million inhabitants and highly developed economics, technology and transport. At the same time, the Taiwan and Philippines region (TWPH) $\left(117-129^{\circ} \mathrm{E}, 5-26^{\circ} \mathrm{N}\right)$ is a location with most frequent and intense tropical cyclone (TC) influence in the world. Taiwan on average each year can be hit by 3 - 4 TCs (Lu et al. 2013), and the Philippines by 18 TCs (Corporal-Lodangco and Leslie 2017). In total, each year on average the TWPH region can be hit by $\sim 22 \mathrm{TCs}$, which is approximately $80 \%$

\footnotetext{
* Corresponding author

E-mail: mongminglu@ntu.edu.tw
}

of all TCs formed over the western North Pacific (WNP). To understand and document the tropical cyclone climatology and variability in TWPH region certainly is not only of great scientific importance but also of great societal and economic value for the safety and wellbeing of people in this region.

The TC season in Taiwan is from June through November and peaks in August. During January to March there is no TC activity around Taiwan. The majority of affecting Taiwan TCs are formed over the western Pacific and the Philippine Sea warm pool (Lu et al. 2010). After formation, these storms usually take one of the following popular paths. The first one is to move northwestward and make landfall 
in Taiwan or South China. The second is to move northwestward then recurve near $25^{\circ} \mathrm{N}$ before approach eastern China, Korea, and Japan, and the last is to move to the open ocean of the North Pacific (Tu et al. 2009). The TCs with similar origins may result in very different paths. The influence on the land area is largely determined by the tracks and complex topographic effect. The TC track patterns were considered as the primary predictors by studies of rainfall and landslide modeling in Taiwan (Lee et al. 2006). Several objective TC track classification methods have been proposed and applied to seasonal prediction (Chu et al. 2010; Lin et al. 2015).

Different from Taiwan that has three months of quiet period, the Philippines are affects by TCs all year round. Corporal-Lodangco and Leslie (2017) designed a metrics to summarize the climatology (1945 - 2011) of the Philippine TCs, which is defined as the TCs formed within or entering into the area of $5-25^{\circ} \mathrm{N}$ and $115-135^{\circ} \mathrm{E}$, similar to the official domain of the Philippine Atmospheric, Geophysical and Astronomical Services Administration (PAGASA) Area of Responsibility (PAR) (Gile et al. 2021, Fig. 1). They documented that the Philippine TC activity has two distinct seasons, namely, the less active season (LAS; January to May) and the more active season (MAS; June to December). The median of the LAS TC frequency is 2 counts per year with the interquartile range (IQR) of 2 , while the median of the MAS TC frequency is 15 counts per year with the IQR of 4.5. The landfalling frequency shows a median of 1 in LAS, while it shows a median of 6 in MAS. The time between LAS and MAS can be identified as a TC-break period. The interannual variation of the TC-break period measured as from the end of LAS to the beginning of MAS ranges from 2 days to 5 months, while the TC-break period measured as from the end of MAS to the beginning of LAS ranges from 6 days to 7 months. The large interannual variability of the length of the break period is mainly driven by ENSO.

The TWPH region shows distinctly different TC seasonality in the northern and southern part of the region. The tracks of the TCs entering into the TWPH region respond to the large-scale climate variability on a wide range of the time scales that includes the scales of the sub-seasonal (10 60 days), seasonal (60 - 180 days), interannual (2 - 7 years), interdecadal ( 8 - 20 years), and multi-decadal ( $>20$ years). Chen et al. (2017) investigated the climatological characteristics of the TCs generated over the WNP and moved to the TWPH region. They found that the probability of a WNP TC that moves into the SCS changes with seasons. During August to September only $12-18 \%$ of the WNP TCs moves into the SCS. The probability is much higher during June to July and October to November with the percentages of $25-26 \%$ and $25-32 \%$, respectively. Tan et al. (2019) documented the autumn (September to November) season relationship between the entrance TCs to the SCS and the large-scale variability of ENSO and intra-seasonal oscillation (ISO). The entrance TCs defined in their paper is the TCs born over the WNP and later propagated into the SCS. They classified the ENSO and TC relationship to El Niño-less, El Niño-more, La Niña-less, and La Niña-more four types. They found that the El Niño associated largescale flow in general hindered the TCs moved into the SCS, but during the El Niño-more years the ISO associated large-scale flow overcome the hindrance and helped the TCs propagate into the SCS. During the La Niña-more (La Niña-less) years both La Niña and ISO work coherently to support (suppress) the westward propagation of the entrance TCs. Chen et al. (2020) documented the characteristics of TC tracks of the TCs formed in the SCS and classified the tracks to three major types: northeastward (NE) toward the Philippines and Taiwan, northward $(\mathrm{N})$ toward southern China, and westward-northwestward (W-NW) toward the Indochina Peninsula and southwestern China. They found that in May the major type is NE, in June it changes from NE to W-NW, in July to September the major type changes from W-NW to N, and in October to November type W-NW becomes dominant again. The track patterns are determined by the seasonal evolution of the monsoon trough (MT) and the western Pacific subtropical high (WPSH). They pointed out that TCs tend to follow the propagation pattern of the convection organized by the ISO such as the 10-24-day and 30-60-day waves. Thus, in addition to the seasonal evolution of monsoon and subtropical high, ISOs are another dominant factors influential to the tracks of the TCs formed in the SCS.

The major large-scale environmental flow patterns influential to WNP TC genesis are documented in Ritchie and Holland (1999) and objectively analyzed by Yoshida and Ishikawa (2013). The five major flow patterns are monsoon shear line (SL), monsoon confluence region (CR), monsoon gyre, easterly wave (EW), and Rossby energy dispersion from a pre-existing tropical cyclone. The influence of different flow patterns and other environmental factors such as the local and remote SST anomalies, vertical wind shear, low-level vorticity, the humidity in lower atmosphere, and the theoretical potential intensity are widely investigated using a genesis potential index (GPI) originally proposed by Emanuel and Nolan (2004) and modified and used in many studies to understand the relationship between TC and large-scale environmental conditions (e.g., Murakami and Wang 2010; Li et al. 2013; Wang and Moon 2017; Moon et al. 2018; Choi et al. 2019; Hsiao et al. 2020).

The decadal-scale variability of WNP TCs have been vigorously studied. Liu and Chan (2013) found that the TC activity over the WNP during 1960 - 2011 can be separated to two active periods (1960 - 1974 and 1989 - 1997) and two inactive periods (1975 - 1988 and 1998 - 2011). The Pacific Decadal Oscillation (PDO) may have a significant effect on the TC genesis frequency in the southeast quadrant of the WNP on an interdecadal time scale, although its relation with 
the TC number in the entire WNP is insignificant. Kim et al. (2020) analyzed the data from 1982 - 2013 and found the significant reduction of the TC genesis frequency over the WNP since the late 1990s is caused by asymmetric central Pacific (CP) ENSO properties. More frequent CP La Niña events and less frequent CP El Niño events were observed during a negative PDO phase (i.e., 1998 - 2013) that leads to a reduction in eastern WNP TC genesis as a result of the anticyclonic Rossby wave response over the eastern WNP TC driven by the anomalous SST pattern. Huangfu et al. (2017) analyzed the 1979 - 2013 data and identified a decadal-scale decreasing trend in the WNP TC genesis annual frequency after 1998, while no trend was observed before 1998 . The difference between two epochs show a northwest-southeast orientation over the WNP that resembles an imprint of the MT. MT was weaker during the later epoch than during the earlier. Through energetic diagnosis they showed that the weak MT weakened the barotropic energy conversion in the eastern part of MT due to the weakened meridional shear and mean zonal wind convergence. On the other hand, Ha and Zhong (2015) analyzed the data from 1994 - 2011 to investigate decadal scale variability in SCS TC activity during the boreal summer (June to August). They found that after 2003 the number of TCs formed over the SCS significantly decreased. They attribute the decadal change to the strong subsiding flow over the SCS induced by the strong convection over the Indian Ocean and the western Pacific warm pool where the SSTs became warmer after 2003. They pointed out that affected by the local anomalous easterly flow the ISO over the SCS was weakened after 2003. Weak ISO is unfavorable for the development of synoptic-scale disturbances and may contribute to the decrease in TC activity.

The WNP TCs have two kinds depending on their origins, namely, the SCS or the Pacific. In this paper the former is termed as the SCS-born TCs and the latter the WNPborn TCs. The annual total number of the WNP-born TCs is approximately four times of the number of the SCS-born TCs. Compared with the WNP-born TCs, the SCS-born TCs received much less attention. The purpose of this paper is to use the most recent (1979 - 2018) TC and large-scale climate datasets to document the climatology and variability of the WNP- and SCS-born TCs, in particular their activity in the TWPH region. We attempt to identify the periods that are clearly deviated from climate normal, and then to evaluate the large-scale patterns in order to find out what makes the identified periods different from others. The data and methodology are described in section 2. Section 3 present the forty year climatologcal statistics of the SCS- and WNPborn TCs. The sub-regional variation is presented in section 4. The interannual and decadal variability is presented in section 5. Section 6 is the summary, discussion and conclusions. The results of this study can improve understanding of TC in the TWPH region and enhance the climatological basis for real-time climate monitoring and analysis.

\section{DATA AND METHODOLOGY}

The TC data used in this study is the best track data produced by Regional Specialized Meteorological Center (RSMC), Tokyo, Japan (http://www.jma.go.jp/jma/ jma-eng/jma-center/rsmc-hp-pub-eg/besttrack.html). The RSMC Tokyo-Typhoon Center maintains near-real time update of the TC best track data, JMA best track. It is a big advantage to the present paper when applying the research results to produce real-time climate analysis report in the future. Among other information, the best track data for each TC at 6-h intervals includes latitude-longitude position, maximum sustained surface wind speed, and minimum central pressure. Genesis locations, tracks, and all other TC metrics were generated from the JMA best track data.

For large-scale environment data, the European Center for Medium-Range Weather Forecasts (ECMWF) interim reanalysis (Dee et al. 2011) obtained from ECMWF is used. The variables include the mean sea level pressure (SLP), horizontal velocity ( $\mathrm{u}, \mathrm{v})$, and derived velocity potential (vp) and stream function (sf) derived from $u$ and $v$ using GrADS (http://cola.gmu.edu/grads/). For SST data, the NOAA Extended Reconstructed Sea Surface Temperature (ERSST v5; Huang et al. 2017) of monthly and $2^{\circ} \times 2^{\circ}$ horizontal resolution is used. For the proxy of convection activities, we used National Oceanic and Atmospheric Administration (NOAA) Climate Data Record (CDR) of daily outgoing long-wave radiation (OLR) version 1.2 (Liebmann and Smith 1996; Lee et al. 2011) with $1^{\circ} \times 1^{\circ}$ resolution estimated from High-Resolution Infrared Radiation Sounder (HIRS) radiance observation with a two-day lag.

TC in the present study refers to tropical storms and typhoons that have the maximum sustained wind speed of the surface wind (VMAX) of 35 knot or higher (wind speed $>35 \mathrm{kt}$ ) during the storm's entire lifetime. The TC genesis location is identified as the latitude and longitude of the first record of VMAX that exceeds $35 \mathrm{kt}$. If the location is within the SCS, the TC is categorized as a SCS-born TC. Otherwise, it is categorized as a WNP-born TC.

The basic climatological statistics documented in section 2 include the TC passage or density map, which is calculated at each $1^{\circ} \times 1^{\circ}$ latitude and longitude pixel as the percentage with respect to the total sum of all pixels in the large domain from $100-180^{\circ} \mathrm{E}$, and $0-40^{\circ} \mathrm{N}$ based on 40-yr (1979 - 2018) TC data. The passage map represents the track information showing the influence domain of the WNP TCs. The temporal and spatial patterns of the seasonal characteristics of the TCs over the large WNP domain and in the TWPH region are analyzed based on the TC counts, frequency, and the accumulated cyclone kinetic energy (ACE). The TC ACE definition is the same as in Lu et al. (2018) but slightly different from the ACE that used to measure the activity of individual tropical cyclones and entire tropical cyclone seasons, particularly the Atlantic tropical 
seasons (Bell et al. 2000). The ACE of the present paper refers to the sum of the squares of VMAX measured every six hours when the TC is within the influence domain and only the named system counted. It should be kept in mind that ACE tends to put more weight on intense TC (Yu et al. 2009; Yu and Chiu 2012). The present study focuses on a rather small TWPH region, the other parameters such as TC counts, TC duration and frequency are less robust than ACE in the relationship with large-scale variability.

In this study we analyze the interannual and decadal variability with a specific focus on the spatial patterns of the variability by partitioning the total ACE over the TWPH region by separating the region to four sub-areas, namely, TWN (Taiwan, $117-129^{\circ} \mathrm{E}, 21-26^{\circ} \mathrm{N}$ ), LUS (Luzon Strait, $117-129^{\circ} \mathrm{E}, 16-21^{\circ} \mathrm{N}$ ), PHN (Philippines North, $117-129^{\circ} \mathrm{E}, 11-16^{\circ} \mathrm{N}$ ), and PHC (Philippines Central, 117 $\left.-129^{\circ} \mathrm{E}, 6-11^{\circ} \mathrm{N}\right)$. The southern tip of the Philippines is located near $4^{\circ} \mathrm{N}$. The two sub-areas PHN and PHC cover the active domain of the TCs that are influential to the Philippines that is almost the entire Philippine territory.

\section{SCS-BORN AND WNP-BORN TROPICAL CYCLONES}

During the recent four decades (1979 - 2018) the total count of the numbered TCs in the JMA best-track data is 1024 , including 18 TCs that were formed to the east of the dateline and later moved westward across the dateline into the WNP. These $18 \mathrm{TCs}$ are ignored in order to focus the study on the WNP- and SCS-born TCs. The average annual TC genesis number of the WNP- and SCS-born TCs is 20.4 and 4.8, respective. Figure 1 shows the genesis frequency based on the total counts on the $1^{\circ} \times 1^{\circ}$ mesh grid during the forty-year period. A southeast-northwest oriented region with the southeast tip point at $\left(145^{\circ} \mathrm{E}, 10^{\circ} \mathrm{N}\right)$ and the northwest tip point at $\left(115^{\circ} \mathrm{E}, 18^{\circ} \mathrm{N}\right)$ can be identified as a favorable region for TC genesis, where the TCs are more frequently formed than in other regions. This is the location of the boreal summer MT (e.g., Huangfu et al. 2017), the cradle of WNP TCs (Molinari and Vollaro 2013). Figure 2 shows the frequency of TC passage which sums the counts of 6-hourly data in the record at each $1^{\circ} \times 1^{\circ}$ mesh grid. In other words, it has the information of frequent traveling routes of the TCs in addition to the genesis location. It clearly shows that the Luzon Strait between Taiwan and Luzon island of the Philippines and the SCS and the Philippine Sea are the hotspots for TC passage. The figure reflects two types of the favorable passage patterns, namely, the northward and westward types that often occur during the summer (June to August) and autumn (September to November) seasons, respectively (see Fig. 1 in Lu et al. 2018).

To illustrate the seasonality of the TC activity the integrated TC passage density is presented in the latitude-time and time-longitude cross sections in Fig. 3. The latitudetime distribution of the TC passage density integrated over the longitudial band from $110-180^{\circ} \mathrm{E}$ shows a seasonal peak in the four months of July to October with clear southward shift of the peak associated with the change of seasons from boreal autumn to winter. In the higher-latitudes to the north of $26^{\circ} \mathrm{N}$, the peak appears in August and September. In the tropics to the south of $14^{\circ} \mathrm{N}$, the peak appears in October and November. Note that the focus region of this study, TWPH, covers the latitudinal range from $5-26^{\circ} \mathrm{N}$. The contrast between the subtropics and tropics can be seen in the longitude-time distribution of the TC passage density integrated over the latitudinal belts from $0-20^{\circ} \mathrm{N}$ (Fig. 3b) and $20-35^{\circ} \mathrm{N}$ (Fig. 3c). The tropical TC activity peaks in October and is more active during the latter half of the WNP TC season (September to December). The subtropical TC activity peaks in August to September and is more active during the months of July to October with a much wider spread in longitudes. It is interesting to see the sharp decline

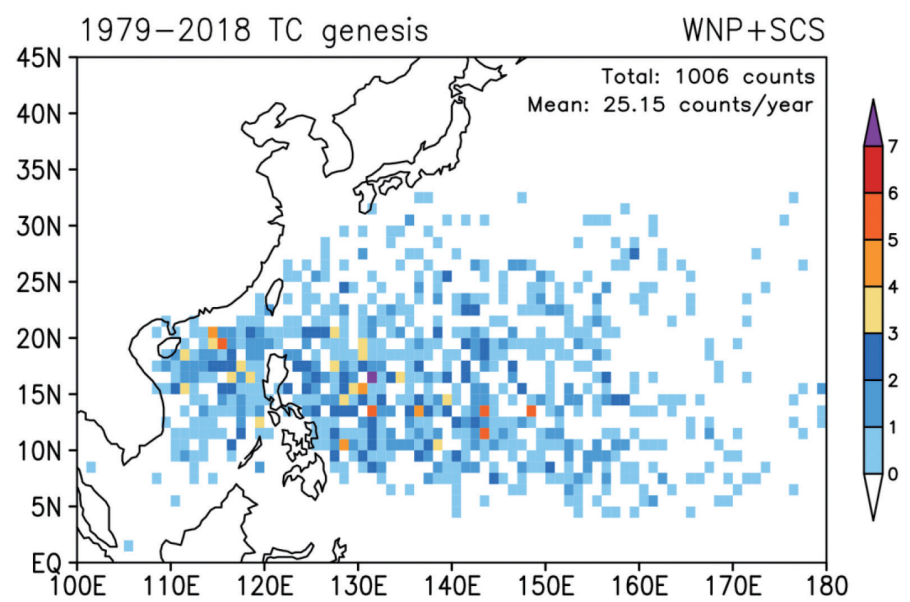

Fig. 1. The spatial distribution of the genesis location of western North Pacific tropical cyclones during the 40 years from 1979 - 2018 presented in the 1- by 1-degree longitude-latitude grid. 


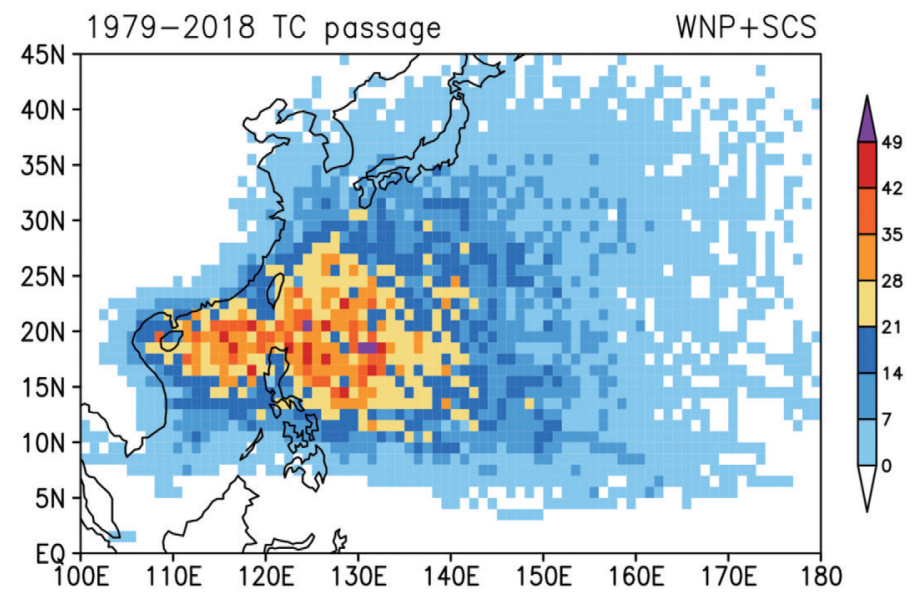

Fig. 2. The spatial distribution of tropical cyclone total passage during the 40 years of $1979-2018$. The passage is calculated as the total number of the six hourly tropical cyclone data reported in the JMA best track dataset. The distribution is presented in the 1- by 1-degree longitude-latitude grid.
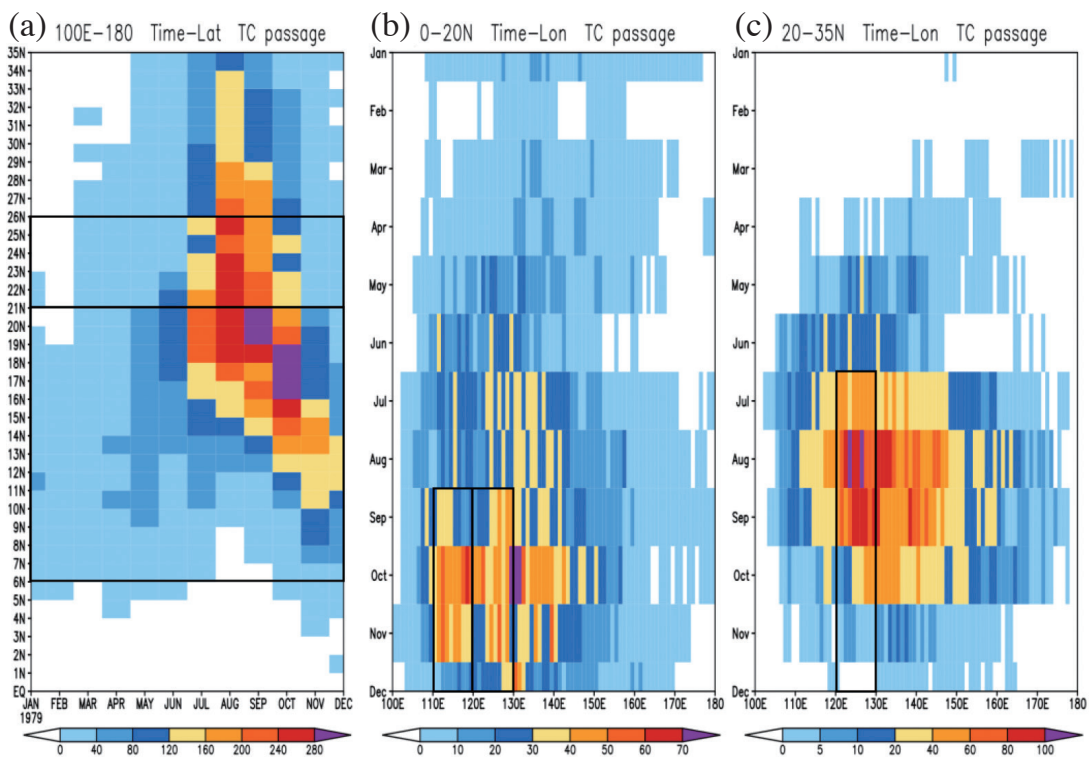

Fig. 3. The tropical cyclone total passage during the 40 years of from $1979-2018$ (a) summed over the longitudes of from $100^{\circ} \mathrm{E}-180^{\circ}$ presented in the time-latitude cross section, (b) summed over the tropical latitudes of $0-20^{\circ} \mathrm{N}$, and (c) summed over the extratropical latitudes of $20-35^{\circ} \mathrm{N}$ presented in the longitude-time cross section. The boundary latitudes of the Taiwan and Philippine region (TWPH) and Taiwan sub-area (TWN) are marked in black in (a). The boundary longitudes of the South China Sea and the Philippine Sea are marked in black in (b) and (c). 
of TC activity after October in the subtropics. The seasonal change in the tropics is not as sharp as in the subtropics.

Different climatological features of the WNP- and SCS-born TCs are clearly shown in the passage maps (Fig. 4). In contrast to the vast influence domain of the WNP-born TCs (Fig. 4a), the SCS-born TCs can only influence a much smaller domain confined within the maritime area and the coastal and island regions surrounding the SCS (Fig. 4b). A vast WNP maritime region including the coastal regions and islands located along the western rim of the $\mathrm{Pa}-$ cific is within the influence of the WNP-born TCs.

The variability of the WNP TCs from the sub-seasonal to inter-decadal time scales have received tremendous research interest in recent years (e.g., Li and Zhou 2018 and references therein). The forty-year (1979 - 2018) timeseries of the annual total counts (Fig. 5a) shows a distinct decadalscale change occurred around 1994 - 1995 that leads to an inactive period of TC genesis from 1998 - 2011. During the period of 1998 - 2011 only two $(2001,2004)$ in 14 years showing the above 40-year mean (the dashed line in Fig. 5a) annual total TC counts. Note that in 1994 the WNP-born TC count is 26 but it dropped to 9 in 1998. Although the recovering after 1998 is evident, which shows the TC count reached 26 again in 2004, but the count dropped back to 10 in 2010 and remained below the 1986 - 1994 mean until 2018. The WNP-born TCs during recent two decades (1999 - 2018) are in general below the average annual count before $1994(1979-1994)$. Note that during the inactive period of the WNP-born TCs, the SCS-born TC genesis is more active than other years. After 1994 we see it in Fig. 5a that the SCS-born TCs first show few years (1995 - 2002) of more frequent TC genesis, then show large interannual fluctuation with less-TCs periods (2003 - 2006, 2014 - 2015) and more-TCs periods (2008 - 2009, 2013, 2017 - 2018). The distinct peak value of 10 counts in 2017 is an extreme. Our findings confirmed Li et al. (2019) where the period of 1994 - 2002 was documented as a high frequency period of summer (July to September) TC genesis over the SCS. They found the autumn (October to December) TC genesis frequency abruptly changed from high to low in the early 2000s, as the subtropical high strengthened over the SCS.

In addition to the interannual and interdecadal fluctuation patterns, the WNP- and SCS-born TCs also have different climatological seasonality as shown in the distribution of TC genesis totals counted on the monthly basis (Fig. 5b). The most favorable time for TC genesis is August and September when the WNP- and SCS-born two types are counted together. The average genesis frequency is approximately 5 TCs per month during August and September, of which about $15-18 \%$ are formed over the SCS. In November, the SCS-born TCs count almost $40 \%$ of the total TCs, which is the largest portion that the SCS-born can contribution to the yearly WNP totals.

\section{THE TAIWAN-PHILIPPINE REGIONAL AND SUB-AREA MEAN TC ACTIVITY}

The climatological mean and variability of affecting Taiwan and the Philippines TCs are documented in this section. The Taiwan-Philippine region, TWPH, was defined in section 1 as a rectangular region with the longitude and latitude boundaries as $117-129^{\circ} \mathrm{E}$ and $5-26^{\circ} \mathrm{N}$. The region was particularly chosen with the real-time climate services in mind, which usually demands fine-scale climate information such as the variations within TWPH. Therefore, as described in section 2, we separate TWPH to four sub-areas, namely, TWN, LUS, PHN, and PHC. The latitudinal boundaries of TWN is $21-26^{\circ} \mathrm{N}$, LUS $16-21^{\circ} \mathrm{N}$, PHN $11-16^{\circ} \mathrm{N}$, and PHC $5-11^{\circ} \mathrm{N}$. The WNP-born TC passage map in TWPH (Fig. 6a) shows the most frequent TC activity sub-area is LUS, and the second is TWN. The SCS-born TC passage map (Fig. 6b) shows that LUS remains as the most frequent TC activity sub-area, TWN is the second. The dramatically frequent TC influence to LUS is even enhanced when seeing the combined passage of SCS- and WNP-born TCs (Fig. 6c). The high TC passage in the Pacific side of TWN is striking.

The four sub-areas have distinctively different seasonality. Figures $7 \mathrm{a}-\mathrm{c}$ show the monthly percentage of (a) 1979-2018 TC passage WNP-born

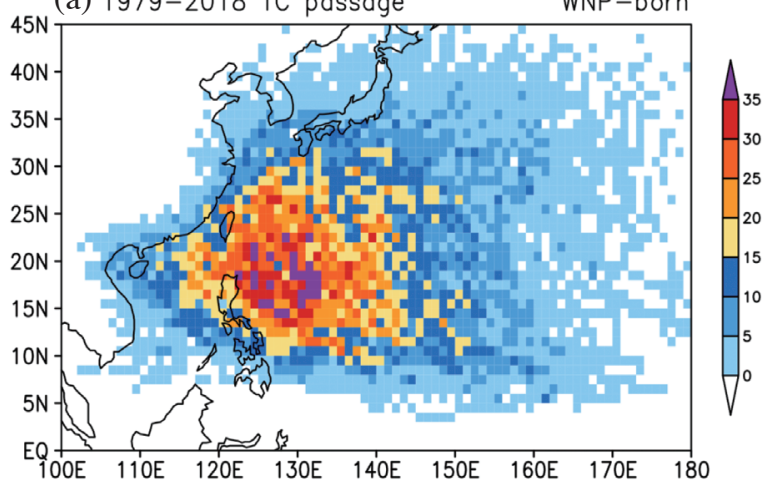

(b) 1979-2018 TC passage

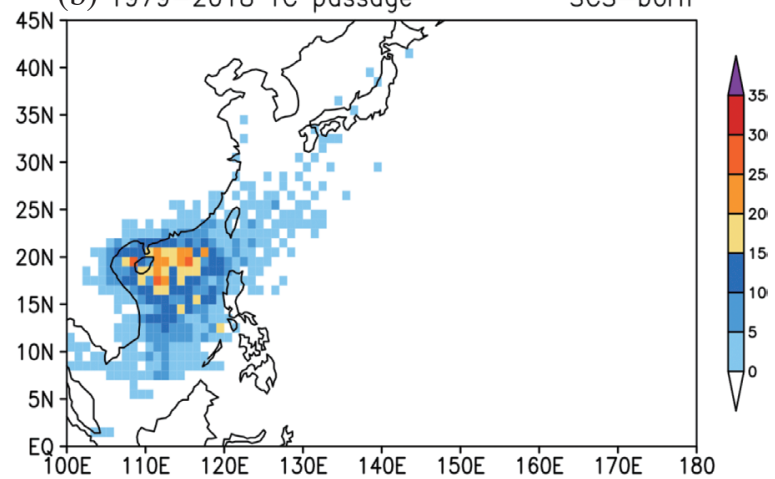

Fig. 4. The same as Fig. 2, but for tropical cyclones formed over (a) the western North Pacific (WNP) and (b) the South China Sea (SCS). 


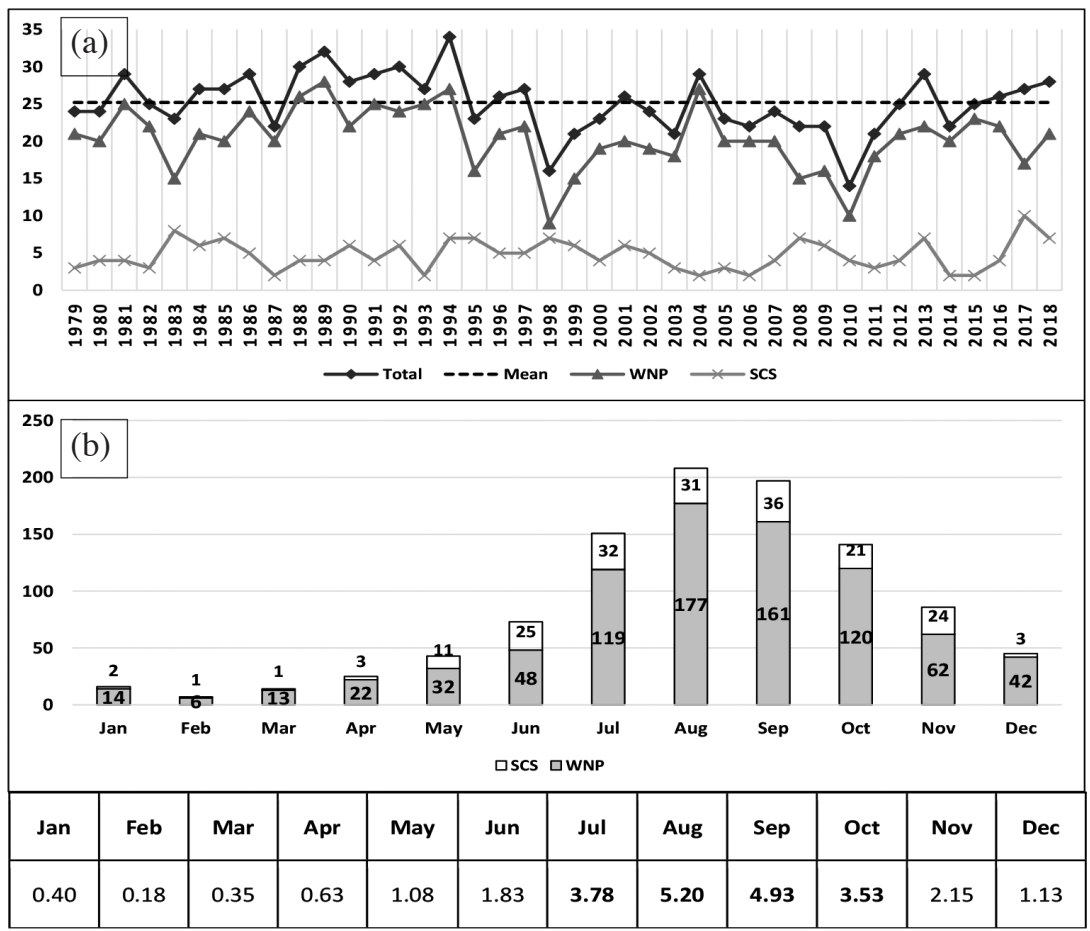

Fig. 5. (a) The 1979 - 2018 time of the annual (i.e., January to December) counts of the tropical cyclones (TC) formed over the western North Pacific (WNP) (marked by $\boldsymbol{\Delta}$ ), the South China Sea (SCS) (marked by $\boldsymbol{x}$ ) and both ocean basins (Total, marked by $\boldsymbol{\bullet}$ ). (b) The $1979-2018$ TC counts summed by months of the WNP- (shaded bars) and SCS-born (open bars) TCs. The 40-year average counts of the TCs formed in each month is presented in the bottom table.
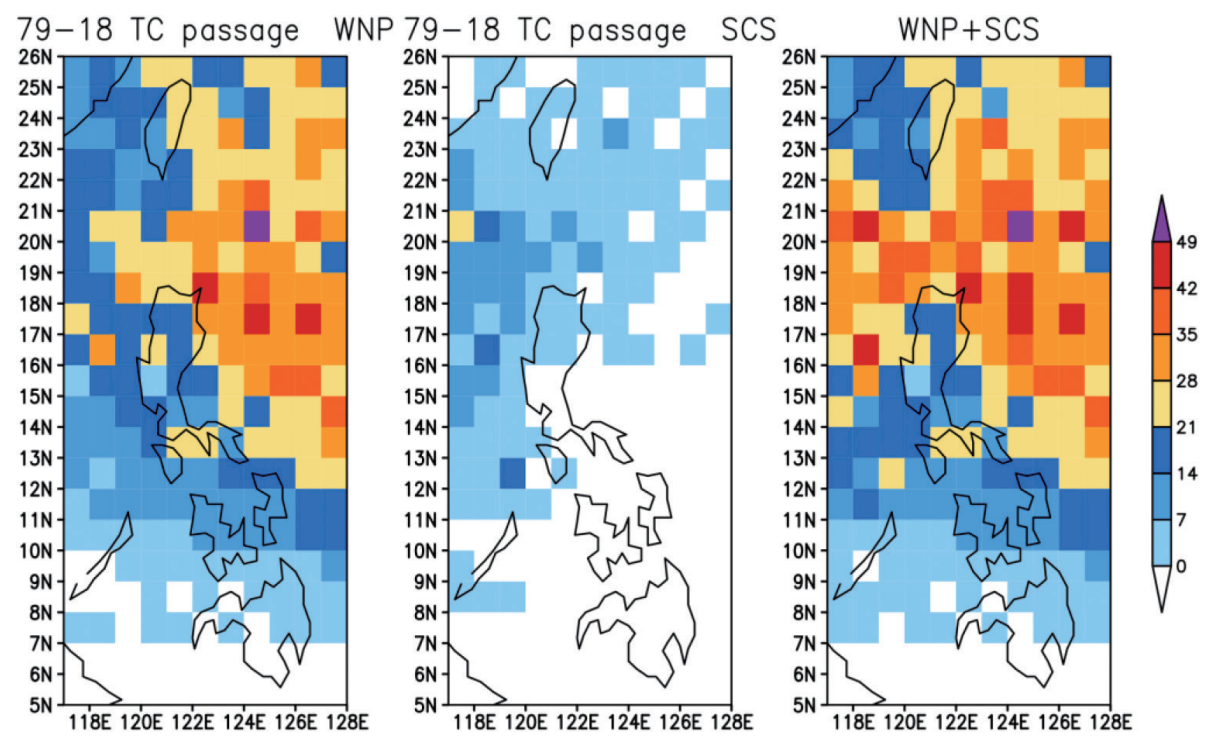

Fig. 6. The tropical cyclone passage as in Figs. 3 and 4 but focus on Taiwan and Philippines region (TWPH) $\left(117-129^{\circ} \mathrm{E}, 5-26^{\circ} \mathrm{N}\right)$. The four subareas, namely, TWN, LUS, PHN, and PHC, are the four rectangular box region from top to bottom bounded by the latitudes of $21-26^{\circ} \mathrm{N}, 16-21^{\circ} \mathrm{N}$, $11-16^{\circ} \mathrm{N}$, and $6-11^{\circ} \mathrm{N}$, respectively. The panels from left to right are the passages of WNP-born, SCS-born, total TCs, respectively. 


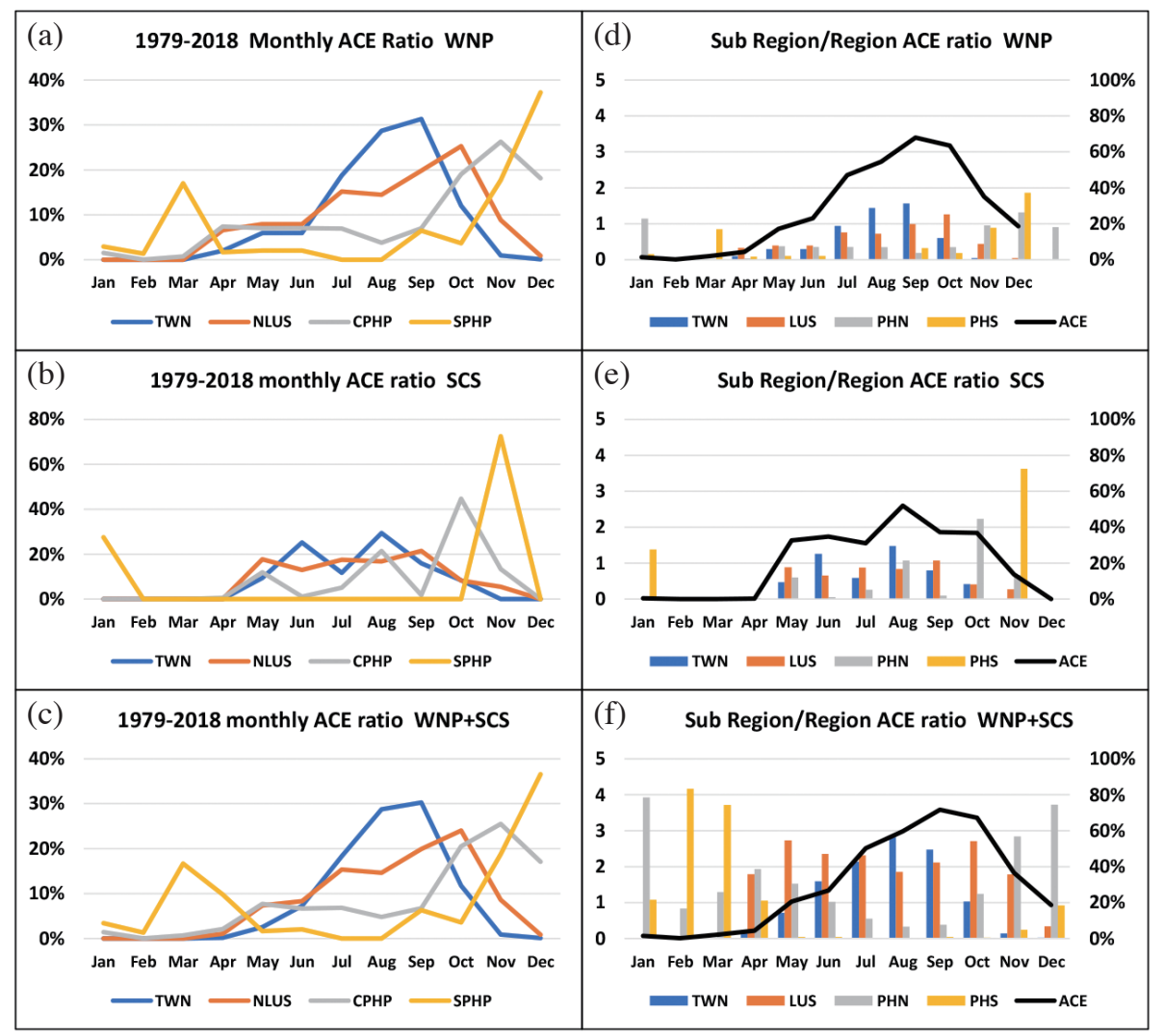

Fig. 7. The climatological characteristics of the accumulated cyclone kinetic energy (ACE) of the tropical cyclones (TC) formed over the western North Pacific (WNP), the South China Sea (SCS), and both (WNP + SCS) that moved into the four sub-areas of TWN, LUS, PHN, PHC as in Fig. 6. (a) - (c) are sub-area statistics of the monthly percentage of the annual total ACE for the WNP-born (a), SCS-born (b), and sum (c) TCs. (d) - (f) are the percentage (bars) of the ACE in the Taiwan and Philippines region (TWPH) $\left(117-129^{\circ} \mathrm{E}, 5-26^{\circ} \mathrm{N}\right)$ total ACE (black line, unit: $\left.10^{5} \mathrm{kts}{ }^{2}\right)$ accounted for each sub-area on monthly basis, the sub-area TCs with the origins of WNP-born (d), SCS-born (e), and together (f) are presented separately. The left/right y axis label in (d) - (f) is the ACE/percentage.

the annual total ACE over each sub-area for the WNP-born (Fig. 7a), SCS-born (Fig. 7b), and all (Fig. 7c) TCs. The right column in Fig. 7 shows the contribution of each subarea to the regional total ACE in TWPH on the monthly basis averaged over the 40 years, for the WNP-born (Fig. 7d), SCS-born (Fig. 7e), and all (Fig. 7f) TCs. To the regional total ACE, the contribution of SCS-born TCs is much less than the WNP-born TCs, the difference between the WNP-born TC ACE curves (Fig. 7a) and all TC ACE curves (Fig. 7c) in the same sub-area is almost not distinguishable. The relative portion of different sub-area contribution to the TWPH total ACE shows strong seasonal features. During the winter and spring months of January to March the contributions mainly come from PHN and PHC, although the rare occurrence of TCs resulting in small regional total ACE. During May and June, the main contribution to the TWPH regional ACE comes from LUS, while the contribution from TWN is more than LUS in June for the SCS-born TCs. During July, TCs are active in TWN and LUS, while the SCS-bore TCs are more active in LUS than TWN. During August and September, TCs in TWN are more active than in LUS, while the SCS-born TCs are more active in LUS than in TWN. TC activity in TWN rapidly decreases in October and continually weakens to the end of a year. Clear seasonality difference between the SCS- and WNP-born TCs in TWPH region is evident. The seasonal commencement and ceasing of the SCS-born TCs over TWPH (Fig. 7e) shows rather rapid change compared with the WNP-born TCs. Note that the seasonality of the regional and sub-area TC ACE revealed here is of fundamental importance to seasonal TC forecast in TWPH region. TC ACE is an integrated value that takes the TC count, intensity and duration into account. It is an useful predictor for seasonal forecast because it shows high correlation with the TC related economic loss (e.g., Lu et al. 2013).

The spatial variation of the peak months of the TC ACE can be explained by the seasonal characteristics of the major large-scale flow patterns of the Asian-western North Pacific summer monsoon (Fig. 8), such as the western North Pacific subtropical high (WNPH) and the South Asia-western Pacific monsoon trough (SA-WPMT) (Tu et al. 2009). Figure 8 shows that in July the WNPH ridge extended from 
(a) 1979-2018 mean SST SF850

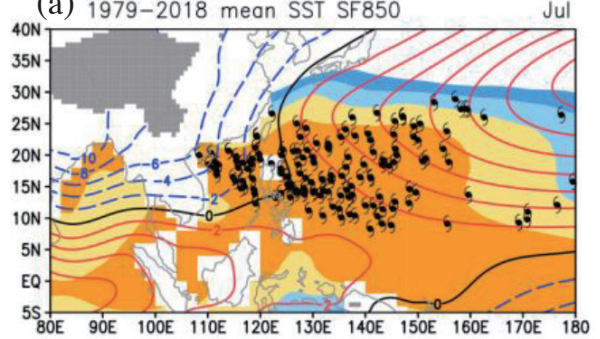

(b) 1979-2018 mean SST SF850

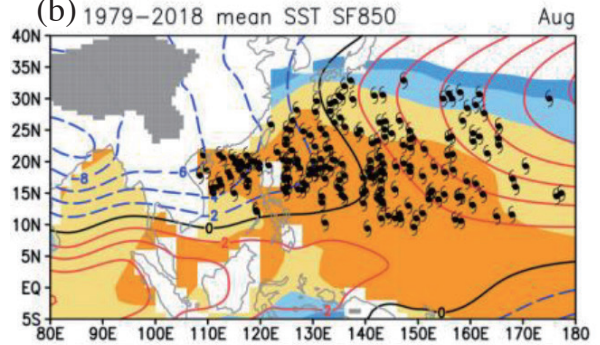

(c) 1979-2018 mean SST SF850

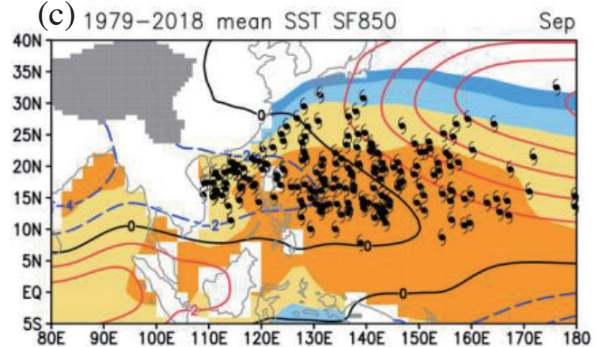

(d) 1979-2018 mean SST SF850

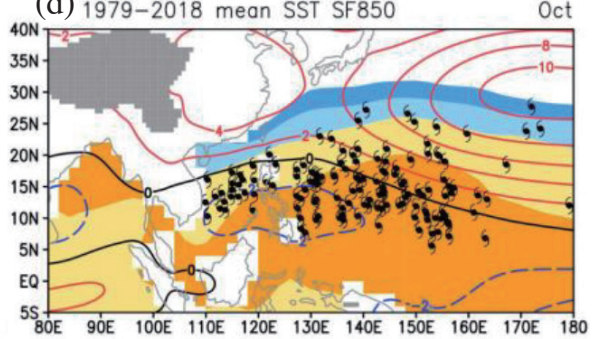

(e) 1979-2018 mean SST SF850
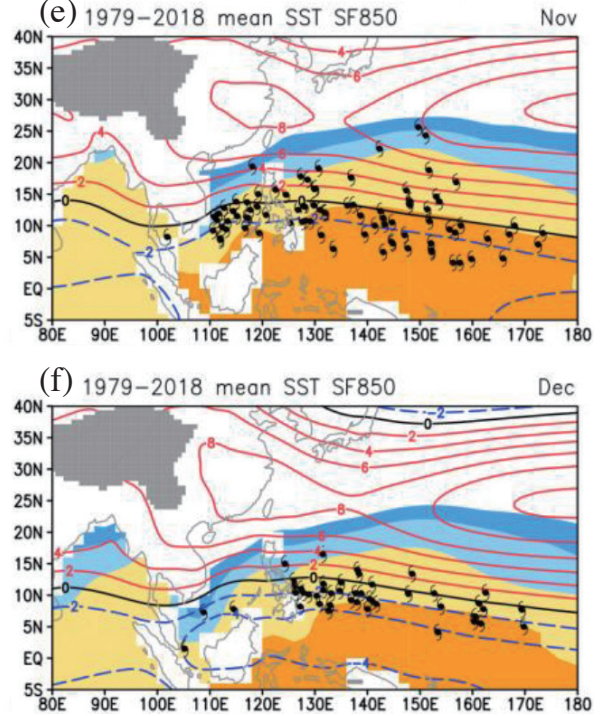

Fig. 8. The 1979 - 2018 average monthly climatology of the sea surface temperature (SST, unit: ${ }^{\circ} \mathrm{C}$ ) (shading) and 850 -hPa stream function (contour, red: positive, blue: negative, black: zero, unit: $10^{5} \mathrm{~m}^{2} \mathrm{~s}^{-1}$ ). (a) - (f) are for the months of from July to December, respectively. The genesis locations of the tropical cyclones occurred during the 40 years are marked by the black dots.

the high pressure center $\left(180^{\circ} \mathrm{E}, 30-35^{\circ} \mathrm{N}\right)$ slightly slanted along the latitudes of $25-30^{\circ} \mathrm{N}$ in southwest direction toward southeast China and Taiwan. The WNPH intensifies in August with the center located to the north of $30^{\circ} \mathrm{N}$. A monsoon trough extended from southeast Asian continent to the SCS and further to the western Pacific warm pool positioned in the northwest-southeast direction. In September the low pressure center of the SA-WPMT appear along 10 $15^{\circ} \mathrm{N}$, and the high pressure center of the WNPH to the east of $130^{\circ} \mathrm{E}$ appears at the latitudinal belt of $25-30^{\circ} \mathrm{N}$. The large-scale pattern and strong pressure gradient between the SA-WPMT and WNPH form a favorable condition to sustain the TC activity in the TWPH region and particularly in the northern part such as TWN. The large-scale flow change from September to October is quite dramatic. The SA-WPMT breaks into two centers with an east center over the Bay of Bengal and a west center over the western $\mathrm{Pa}$ cific warm pool. The high pressure center of the WNPH is located along $25-30^{\circ} \mathrm{N}$ and weakly linked with the high pressure center over China to the east of the Tibetan Plateau. The latitudes of WNPH and WPMT centers shift southward as the season marches from boreal autumn to winter. In December (Fig. 7f) the negative stream function straddles over the equator that covers Boneo and the western Pacific warm pool to the north of New Guinea resembles the WPMT during the autumn season.

\section{INTERANNUAL AND DECADAL VARIABILITY}

The interannual and decadal variability of the TWPH regional TC ACE can be seen in the timeseries of the annual total ACE (Fig. 9a). Based on the ACE mean values and variance, the 40 -year period of study can be segmented to three epochs, namely, the weak interannual fluctuation period (1979 - 1996), the persistent low-ACE period (1997 - 2002), and the strong interannual fluctuation period (2003 - 2018). Two change points at 1997 and 2003 were identified using cumulative sum method (Taylor 2000). The mean value and standard deviation of the ACE during the first period $(1979-1996)$ are $4.95 \times 10^{5}$ and $1.13 \times 10^{5} \mathrm{kts}^{2}$, respectively. The mean and standard deviation of the ACE during the second period (1997 - 2002) are $2.63 \times 10^{5}$ and $8.8 \times$ $10^{4} \mathrm{kts}^{2}$, and during the third period (2003 - 2018) are 4.62 $\times 10^{5}$ and $1.52 \times 10^{5} \mathrm{kts}^{2}$. An alternative intuitive way to see the three epochs is using the ACE in 1995 as a benchmark. It is evident in Fig. 9a that all eighteen years (1979 - 1996) 


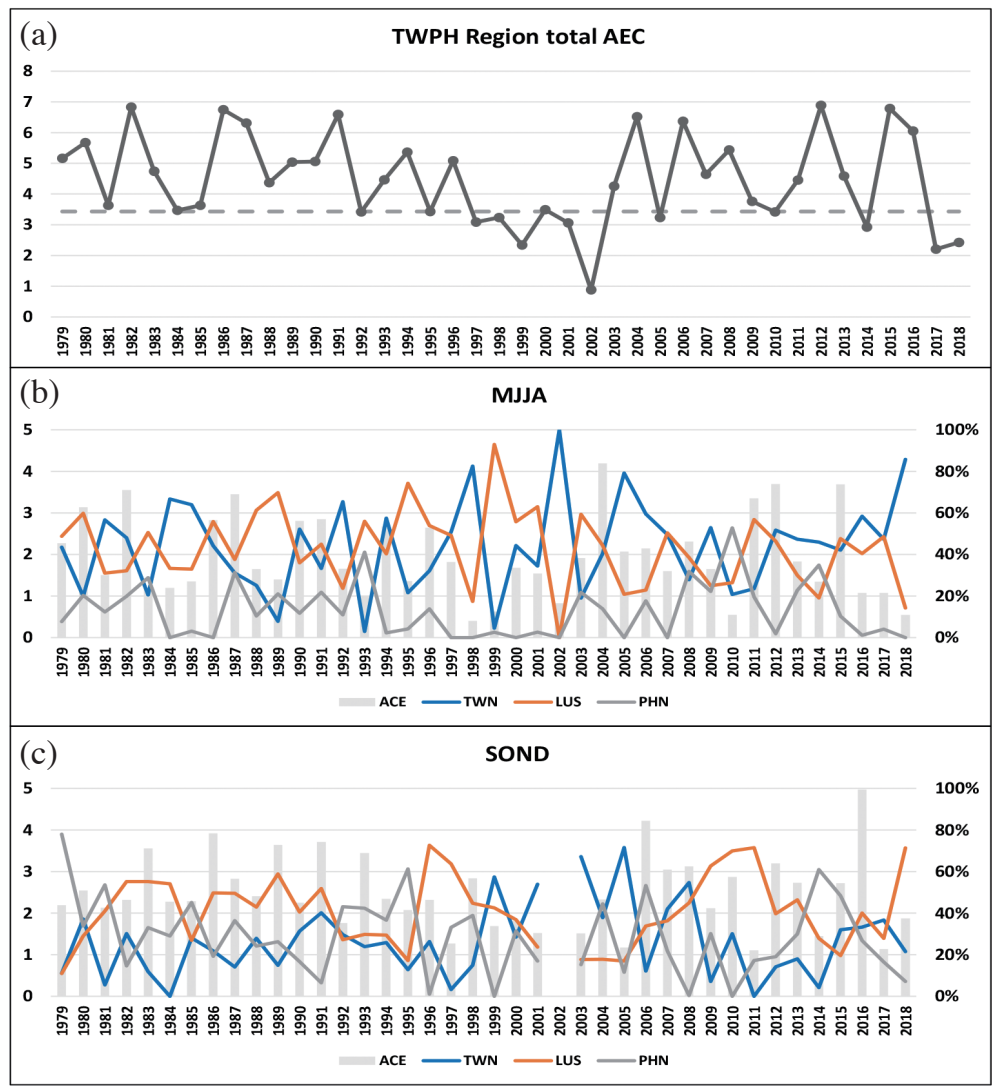

Fig. 9. Time series of (a) the annual (i.e., January to December) total (b) the earlier tropical cyclone (TC) peak season (i.e., May to August), and (c) the latter TC peak season (i.e., September to December) accumulated cyclone kinetic energy (ACE) over the Taiwan and Philippines region (TWPH) $\left(117-129^{\circ} \mathrm{E}, 5-26^{\circ} \mathrm{N}\right.$ ) (grey bars, unit: $10^{5} \mathrm{kts}^{2}$ ) and the four sub-area percentages (lines, blue: TWN, red: LUS, black: PHN, unit: \%) during 1979 - 2018. The left/right y axis label is the TWPH TC ACE/four sub-area percentages. The dashed line in (a) is the annual total ACE in 1995 used as a benchmark to contrast the low-ACE epoch of $1997-2002$.

during the first epoch are above-the-benchmark values except 1992, which is slightly below the benchmark. However, during the second epoch the ACEs of successive six years (1997 - 2002) are below-the-benchmark except 2000 which is marginally higher than the benchmark. Since the ACE difference between 1992 and 1995, and 2000 and 1995, are both within 10 percent of the standard deviation of the entire 40 years or different epochs, we can ignore the difference of 1992 and 2000 to the benchmark and consider the ACEs in these two years are not distinguishable from the benchmark year. By doing so we identify five years $(2005,2010,2014$, $2017,2018)$ as equal to or below the benchmark during the third epoch (2003 - 2018). Note that among these five years, 2017 and 2018 have the ACE values as the second and third lowest in 40 years. During the third epoch the occurrence frequency of low-ACE years is twice of the occurrence frequency during the first epoch. Given the situation that 2017 and 2018 are the second and third lowest years, we interpret the implication as that occurrence possibility of low ACE remains high up to the present time compared with the years before 1997. In contrast to the high occurrence rate of the low-ACE years, the occurrence rate of high-ACE years dur- ing the first and third epochs are similar. The four years (1982, 1986, 1987, 1991) with highest ACEs during the first epoch and the four years $(2004,2006,2012,2015)$ with highest ACEs during the third epoch showing similar magnitude of the ACE values. The occurrence frequencies, four out of eighteen years in the first epoch and four out of sixteen years in the second epoch, are also similar during two epochs. Thus, we can conclude that the most outstanding feature revealed by the 40 -year timeseries of the TC ACE in TWPH is the persistent occurrence of the low-ACE years for six years during the second epoch. The phenomenon is unique. More importantly, it signifies a shift of the regional TC climate from a less variable state during the first epoch to a more variable state during the third epoch. Although the TC ACE variability is largest during the third epoch, the standard deviation difference between the first and third epochs is not significantly large. We will focus on the difference between the unusually low TC activity period (1997 - 2002) and other two periods in the following discussion.

Figures $9 b$ and $c$ illustrate the timeseries of the sub-area percentage of the total ACE for the earlier (May to August, MJJA) and latter (September to December, SOND) TC 
seasons, respectively. We can conceptually deduce a general characteristics of the temporal and spatial variability of TC activity within TWPH region based on the plots. As discussed in section 4 that the TC activity in four sub-areas shows distinctly different seasonality, the annual ACE is separated to MJJA and SOND in order to reveal regional details of the variability. The earlier season timeseries (Fig. 9b) shows a clear out of phase relationship between the TWN and LUS percentages with the correlation coefficient as high as -0.80 . It reflects the fact that during the earlier season the TWPH ACE is to a large extent partitioned between TWN and LUS. It is interesting to note a rare case in 2002 where Fig. 9b shows zero ACE over LUS, which means that there was absolutely no TC activity within the sub-area of LUS. The percentage of LUS ACE (the orange line in Fig. 9b) after 2002 is on average lower than that before 2002. When the ACE percentage is low in LUS, the compensating contribution is found in TWN and PHN (the blue and black lines in Fig. 9b). In contrast to the earlier season, the correlation between TWN and LUS during the latter season is less negative (-0.39). The unusualness in 2002 is more striking in Fig. 9c which shows no TC activity in the entire TWPH region. During the SOND in 2002 only one TC was detected in TWPH and its neighbor region. According to the document issued by Hong-Kong Observatory (https://www.weather.gov.hk/ en/publica/tc/files/tc2002.pdf) the tropical storm Hagupit that first developed as a tropical depression near Dongsha Island in the SCS, later moved in the west-northwest direction finally made landfall near Yangjiang in western Guangdong, China. Because Hagupit reached tropical storm intensity after moving out of the TWPH region, it was not included in Fig. 9, and therefore, there was indeed no TC activity in the entire TWPH region. Figure 9c shows that the persistent low-ACE period over the TWPH region from $1997-2002$ is mainly resulted from the unusually weak TC activity in the sub-area of PHN.

The large-scale condition in the earlier and latter TC seasons during the low-ACE epoch is shown in Figs. 10 and 11 to depict the anomalous patterns associated with the unusual TC climate in TWPH. Figure 10 shows the OLR and SST anomalies during 1997 - 2002 with respect to the climatology averaged over 30 years formed by two separate 15-year periods of 1979 - 1993 and $2003-2017$. The differences between 1997 - 2002 and the individual 15year climatological mean (figures not shown) show similar results as the differences with the 30-year climatological mean. The important features revealed in Fig. 10 that are highly relevant to the TC activity are as follows. In JJAS (Fig. 10a), we observe a zonal belt of negative OLR anomalies extended from Tibetan Plateau to Taiwan along the latitudes of $20-30^{\circ} \mathrm{N}$. It reflects strong convective activity associated with Asian summer monsoon. To the south of the enhanced convection region, we see a large area of suppressed convection represented by the positive OLR anoma- lies extended from the SCS to the western Pacific warm pool region. The convection is also enhanced in many equatorial areas such as west Africa, Indian Ocean, central and eastern Pacific, but suppressed in western Pacific and Southeast Asia. In addition to the convection anomalies, significant SST anomalies are observed in the Northern Hemispheric mid-latitude west Pacific and Atlantic, the South west Indian Ocean, and the west and central Pacific in the Southern Hemisphere. The suppressed convection over the southern SCS and the equatorial western Pacific warm pool region may enhance the warm SST anomalies around the Philippines. In autumn and winter months (Fig. 10b), the SST anomalies show very similar patterns as that in the summer months, but with more areas showing statistically significant anomalies. The negative OLR anomalies over Asian summer monsoon region shifted from $20-30^{\circ} \mathrm{N}$ in JJAS to $0-10^{\circ} \mathrm{N}$ in SOND. Over tropical Africa and west Indian Ocean the enhanced convection appears in a much more areas compared with the earlier season JJAS. The change of the negative OLR anomalies over the Africa and Asian summer monsoon region resembles the seasonal movement of the ITCZ. Enhanced convection is observed over equatorial central and eastern Pacific and strengthened from JJAS to SOND. The warm Indo-western Pacific and cold eastern Pacific patter of SST anomalies appear as a favorable condition to sustain the enhanced ITCZ over the Asian summer monsoon region and stronger Southeast Asian monsoon during SOND. The negative OLR anomalies over eastern Australia reflect enhanced convection during the austral spring and early summer seasons. The OLR and SST anomalies overall suggest that the Asian-Australian monsoon was stronger than normal during the period of 1997 - 2002. As a reminder we should note that only the OLR within the latitudinal belt of $30^{\circ} \mathrm{S}-30^{\circ} \mathrm{N}$ is presented in Fig. 10a because the OLR and convection relationship weakens with the latitudes.

The stream function and wind anomalies at $850 \mathrm{hPa}$ in JJAS (Fig. 11a) show cyclonic circulation anomaly elongated along the latitudes of $20-30^{\circ} \mathrm{N}$ over the western North Pacific. The anomalous stream function pattern is consistent with the more active convection represented by the negative OLR anomalies (Fig. 10a). Over the Pacific it shows negative stream function anomalies in the Northern Hemisphere and positive stream function anomalies in the Southern Hemisphere, which reflects the basin-wide westerly anomalies extended from the northern SCS to the east boundary of South Pacific. The twin cyclonic circulation antisymmetric to the equator located over the western Pacific at $150^{\circ} \mathrm{E}$ $180^{\circ}$ can be interpreted as the Rossby wave response to the enhanced convection over the equatorial central Pacific at $180^{\circ}-150^{\circ} \mathrm{W}$. Figure $11 \mathrm{~b}$ shows that in association with the suppressed convection over the tropical $\left(10^{\circ} \mathrm{S}-10^{\circ} \mathrm{N}\right)$ western Pacific $\left(150^{\circ} \mathrm{E}-180^{\circ}\right)$ a twin anticyclonic pattern emerges over the Philippine Sea and New Guinea Island. Over the Indian Ocean is enhanced cross equatorial flow 
(a) mean JJAS SST OLR anomaly

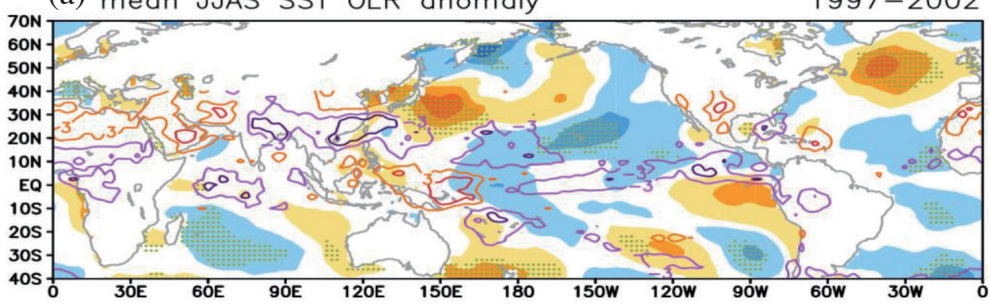

(b) mean SOND SST OLR anomaly

1997-2002

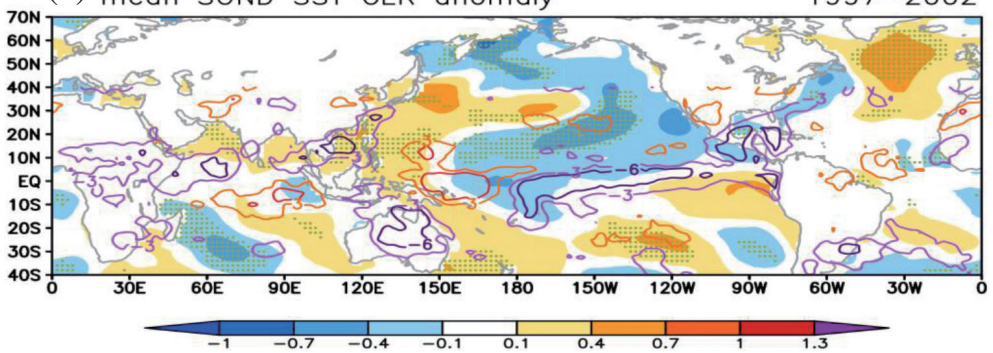

Fig. 10. Spatial distribution of sea surface temperature (SST) (color, unit: ${ }^{\circ} \mathrm{C}$ ) and outgoing longwave radiation (OLR) (contours, purple: negative, orange: positive, unit: $\mathrm{W} \mathrm{m}^{-2}$ ) anomalies for the period of 1997 - 2002 in the (a) earlier (i.e., July to September) and (b) latter (i.e., September to December) peak season of the affecting Taiwan and Philippines region (TWPH) $\left(117-129^{\circ} \mathrm{E}, 5-26^{\circ} \mathrm{N}\right)$ tropical cyclones (TC). The anomalies are calculated based on the 30-year climatology formed by two segments of 1979 - 1993 and $2003-2017$. The grey dots represent statistically significant at the $90 \%$ confidence level. Only OLR within the latitudinal belt of $30^{\circ} \mathrm{S}-30^{\circ} \mathrm{N}$ is plotted.

(a) mean JJAS S850 V850 anomaly 1997-2002

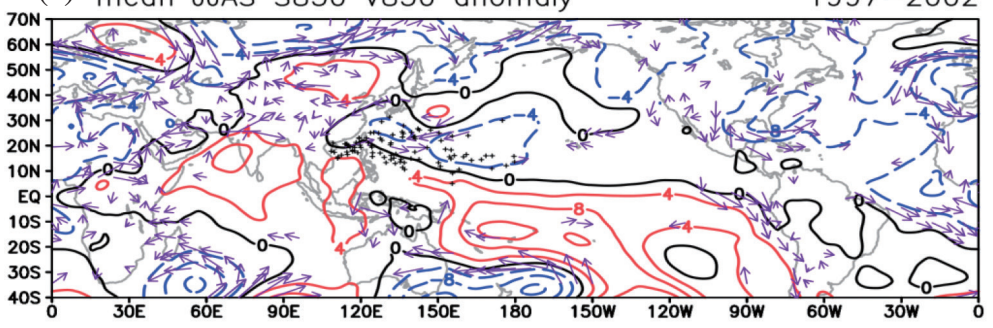

(b) mean SOND S850 V850 anomaly

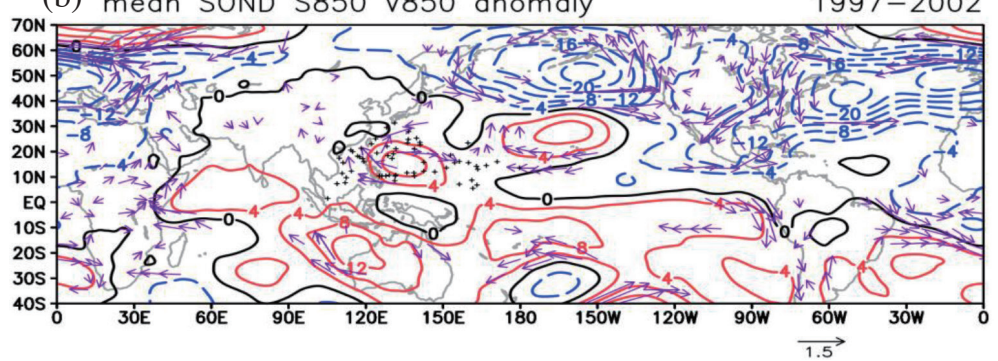

Fig. 11. Spatial distribution of the 850-hPa stream function (contour, unit: $10^{5} \mathrm{~m}^{2} \mathrm{~s}^{-1}$ ) and wind anomalies for the period of $1997-2002$ in the (a) earlier (i.e., July to September) and (b) latter (i.e., September to December) peak Taiwan and Philippines region (TWPH) $\left(117-129^{\circ} \mathrm{E}, 5-26^{\circ} \mathrm{N}\right)$ tropical cyclones (TC) seasons. The anomalies are calculated based on the 30-year climatology formed by two segments of 1979 - 1993 and 2003 - 2017. The crosses represent the genesis locations of the TCs during the period of 1997 - 2002. Only the anomalous winds statistically significant at the $90 \%$ confidence level are plotted. 
near the west coast and the equatorial easterly flow that is connected with the anomalous cyclonic circulation over western Australia. The strong convergent flow formed by the anomalous westerlies near $10^{\circ} \mathrm{N}$, which is associated with the anomalous positive stream function over the North Indian Ocean, and the anomalous easterlies associated with the anticyclonic circulation over the Philippine Sea can enhance the tropical deep convection over northern North Indian Ocean and the SCS shown in Fig. 10b.

\section{SUMMARY AND DISCUSSION}

This paper documents the climatological characters of the WNP TCs, in particular the TC activity in TWPH region, based on the JMA best track data from 1979 - 2018. Understanding the TC activity in TWPH is important for the social and economic prosperity and safety of more than one hundred million people living in this region. It is also of great scientific importance given the fact that every year about $80 \%$ of the TCs formed over the North western Pacific basin can move into this region.

The temporal and spatial variability of WNP TC passage changes with seasons. In the extratopics north of $26^{\circ} \mathrm{N}$ the passage density peaks during the months of August and September, while in the tropics south of $14^{\circ} \mathrm{N}$ the passage density peaks in the autumn months of September to November. Through analyzing the TC data we confirmed previous findings (e.g., Huangfu et al. 2017 and the references therein) that the WNP-born TC counts dropped after 1998. The TC genesis frequency since 1998 has remained lower than the average of 1979 - 1994. However, for the SCS-born TCs we did not observe a drop in the genesis frequency; on the contrary, we observed slight increase in the TC genesis frequency after 1998. The results are also consistent with earlier findings that showed the decrease of WNP TC genesis frequency mainly occurred in the southeast quadrant of the WNP (Liu and Chan 2013; Hsu et al. 2014; Li and Zhou 2014; Ha and Zhong 2015; Hu et al. 2018; Zhang et al. 2018; Zhao et al. 2018).

The spatial characteristics of TC activity within the TWPH region was presented in four sub-areas of TWN, LUS, PHN, and PHC. The sub-areas show distinct differences in TC seasonality. The TC activity in TWN and LUS peaks in the months of July to October. These two sub-areas see much less SCS-born TC influence compared with the influence of WNP-born TCs. In contrast to TWN and LUS, the TC activity in PHN peaks in October and November. PHN sees strongest SCS-born TC influence in October, while strongest WNP-born TC influence in November. The TC activity in PHC is much weaker compared with the other three sub-areas. The TC influence to PHC peaks in November to December. In contrast to TWN where the months of January to March is a TC free period, in PHC during boreal winter and early spring months TC impact can still occur.
An unusual persistent low-ACE period, 1997 - 2002, was identified in this study. Based on the 40-year timeseries of the TWPH TC ACE we found the period of $1979-2018$ can be segmented to three epochs. The earlier 18 years (1979 - 1996) is a period with weaker interannual fluctuation, the last 16 years $(2003-2018)$ is a period with stronger interannual fluctuation, and the middle 6 years (1997 - 2002) is a period with persistently weak TC activity in TWPH region. This period may have important implications since it is a transition phase that signifies a shift of the regional TC climate from a less variable to a more variable state. Different large-scale circulation patterns at $850 \mathrm{hPa}$ in JJAS and SOND, the earlier and latter half of the TC peak season, are investigated over the broad Indo-Pacific region during the low-ACE epoch (Fig. 10). In JJAS, a dipole-like circulation pattern with the northern branch as the anomalous zonally elongated cyclonic circulation centered alone the latitudes of $20-30^{\circ} \mathrm{N}$ and the southern branch as the anomalous clockwise circulation oriented in the northwestsoutheast direction from the Arabian Sea and Indian Ocean through the Indonesian Maritime Continent to the western South Pacific. Over the Indian Ocean the anomalous clockwise circulation straddles over the equator, while to the east of Papua New Guinea the anomalous circulation is located to the south of the equator. Anomalous convection patterns reflected in the OLR anomalies (Fig. 10) are observed as a strong evidence to support the robustness of the anomalous circulation since the OLR and winds are based on two and different datasets. We found that the anomalous cyclonic circulation in the north, the East Asian summer monsoon region, reflects the enhanced ITCZ and monsoon, and thus more active TC activity in the sub-area of TWN. The anomalous anticyclonic circulation in the south, the tropical monsoon region, reflects strong subsidence and suppressed TC activity in the Philippines. In SOND, a pair of anomalous clockwise circulation to the northern and southern sides of the Indonesia Islands is observed. The northern branch is centered over the Philippine Sea and the southern branch is centered over the far eastern Indian Ocean to the northwest of Australia. The anomalous anticyclone over the Philippine Sea is associated with suppressed convection and the anomalous cyclonic circulation over northwestern Australia is associated with enhanced convection over tropical eastern Australia along with the anomalous westerly winds over the Timor and Arafura Seas. The anomalous cyclonic circulation over northwestern Australia can enhance the cross-equatorial flow over the SCS and enhance the positive vorticity which is favorable for SCS-born TC genesis. The anomalous anticyclonic and cyclonic dipole centered over the Philippine Sea and northwestern Australia provides a favorable condition that can enhance autumn convective activity over Southeast Asia and the SCS.

The WNP TC climate regime shift has been discussed in many papers. The decrease of TC genesis frequency 
after late-1990s except a small increase near Taiwan was attributed to the SST variability associated with PDO or IPO (Hsu et al. 2014; Hong et al. 2016; Hu et al. 2018) and the modulation on ENSO diversity and the associated Walker circulation (Huangfu et al. 2018; Zhao et al. 2018). The TC genesis frequency can be influenced by the SST variability through the impacts on the westward extension of the western Pacific subtropical high (Tu et al. 2020), the intensity of the MT that extends from southeast Asia eastward to the Philippine Sea (Huangfu et al. 2017), and the vertical wind shear over the WNP (Liu and Chan 2013; Hong et al. 2016). He et al. (2015) pointed out that the pronounced northward shift of WNP TC activity can be ascribed to the decadal change in tropical Indo-Pacific sea surface temperature. Previous studies (Mei et al. 2015; Zhan et al. 2019) interpreted the anomalous anticyclonic circulation over the Philippine Sea as a descending Rossby wave response to the suppressed convection due to the central Pacific cooling during the negative PDO phase.

In the present study, we identified the period of 1997 2002 as an unique period with unusually persistent inactive TC activity over the TWPH region. The unique phenomenon was associated with the enhanced anticyclonic circulation over the Philippine Sea which is part of the anomalous circulation extended from the North Indian Ocean through the SCS to the South Pacific. It is possible that the TWPH TC activity can be a key feature, together with the associated large-scale patterns and processes it reveals the climate regime transition in the broad Indo-Pacific region on decadal timescales. More studies are needed to understand the inter-ocean teleconnections and the influence on regional TC activity.

Acknowledgements This study is supported by the Ministry of Science and Technology, Taiwan, Grant MOST 110-2111M-002-013-, MOST 108-2111-M-002-009, MOST 1092111-M-002-005, and MOST 105-2923-M-002-012-MY3.

\section{REFERENCES}

Bell, G. D., M. S. Halpert, R. C. Schnell, R. W. Higgins, J. Lawrimore, V. E. Kousky, R. Tinker, W. Thiaw, M. Chelliah, and A. Artusa, 2000: The 1999 North Atlantic and eastern North Pacific hurricane seasons. Bull. Amer. Meteorol.Soc., 81, S19-S22.

Chen, J.-M., P.-H. Tan, L. Wu, J.-S. Liu, and H.-S. Chen, 2017: Climatological analysis of passage-type tropical cyclones from the western North Pacific into the South China Sea. Terr. Atmos. Ocean. Sci., 28, 327-343, doi: 10.3319/TAO.2016.10.04.02. [Link]

Chen, J.-M., P.-H. Lin, C.-H. Wu, and C.-H. Sui, 2020: Track variability of South China Sea-formed tropical cyclones modulated by seasonal and intraseasonal circulations. Terr. Atmos. Ocean. Sci., 31, 239-259, doi:
10.3319/TAO.2019.11.07.02. [Link]

Choi, Y., K.-J. Ha, and F.-F. Jin, 2019: Seasonality and El Niño Diversity in the Relationship between ENSO and Western North Pacific Tropical Cyclone Activity. $J$. Clim., 32, 8021-8045, doi: 10.1175/jcli-d-18-0736.1. [Link]

Chu, P.-S., X. Zhao, C.-H. Ho, H.-S. Kim, M.-M. Lu, and J.-H. Kim, 2010: Bayesian forecasting of seasonal typhoon activity: A track-pattern-oriented categorization approach. J. Clim., 23, 6654-6668, doi: 10.1175/2010jcli3710.1. [Link]

Corporal-Lodangco, I. L. and L. M. Leslie, 2017: Climatology of Philippine tropical cyclone activity: 19452011. Int. J. Climatol., 37, 3525-3539, doi: 10.1002/ joc.4931. [Link]

Dee, D. P., S. M. Uppala, A. J. Simmons, P. Berrisford, P. Poli, S. Kobayashi, U. Andrae, M. A. Balmaseda, G. Balsamo, P. Bauer, P. Bechtold, A. C. M. Beljaars, L. van de Berg, J. Bidlot, N. Bormann, C. Delsol, R. Dragani, M. Fuentes, A. J. Geer, L. Haimberger, S. B. Healy, H. Hersbach, E. V. Hólm, L. Isaksen, P. Kållberg, M. Köhler, M. Matricardi, A. P. McNally, B. M. Monge-Sanz, J.-J. Morcrette, B.-K. Park, C. Peubey, P. de Rosnay, C. Tavolato, J.-N. Thépaut, and F. Vitart, 2011: The ERA-Interim reanalysis: Configuration and performance of the data assimilation system. Q.J. R. Meteorol. Soc., 137, 553-597, doi: 10.1002/qj.828. [Link]

Emanuel, K. and D. S. Nolan, 2004: Tropical cyclone activity and the global climate system. 26th Conference on Hurricanes and Tropical Meteorology, Miami, FL., United States, Amer. Meteor. Soc., 10A.2, 240241. Available at https://ams.confex.com/ams/pdfpapers/75463.pdf.

Gile, R. P., J. C. S. Sugui, J. S. Galang, E. O. Cayanan, H.C. Tsai, Y.-L. Lin, A.-M. Chia, P.-Y. Lin, K.-C. Lu, and B. J.-D. Jou, 2021: Application of Weighted Ana$\log$ Intensity Prediction (WAIP) guidance on Philippine tropical cyclone events. Terr. Atmos. Ocean. Sci., 32, 669-691, doi: 10.3319/TAO.2021.03.03.01. [Link]

Ha, Y. and Z. Zhong, 2015: Decadal change in tropical cyclone activity over the South China Sea around 2002/03. J. Clim., 28, 5935-5951, doi: 10.1175/jclid-14-00769.1. [Link]

He, H., J. Yang, D. Gong, R. Mao, Y. Wang, and M. Gao, 2015: Decadal changes in tropical cyclone activity over the western North Pacific in the late 1990s. Clim. Dyn., 45, 3317-3329, doi: 10.1007/s00382-015-25411. [Link]

Hong, C.-C., Y.-K. Wu, and T. Li, 2016: Influence of climate regime shift on the interdecadal change in tropical cyclone activity over the Pacific Basin during the middle to late 1990s. Clim. Dyn., 47, 2587-2600, doi: 10.1007/s00382-016-2986-x. [Link] 
Hsiao, L.-P., C.-H. Tsou, and J.-Y. Yu, 2020: Investigating the abrupt change of tropical cyclone (TC) activity in the Western North Pacific by using different TC genesis indices. Int. J. Climatol., 40, 5959-5972, doi: 10.1002/joc.6558. [Link]

Hsu, P.-C., P.-S. Chu, H. Murakami, and X. Zhao, 2014: An Abrupt Decrease in the Late-Season Typhoon Activity over the Western North Pacific. J. Clim., 27, 42964312, doi: 10.1175/jcli-d-13-00417.1. [Link]

Hu, F., T. Li, J. Liu, M. Bi, and M. Peng, 2018: Decrease of tropical cyclone genesis frequency in the western North Pacific since 1960s. Dyn. Atmos. Oceans, 81, 42-50, doi: 10.1016/j.dynatmoce.2017.11.003. [Link]

Huang, B., P. W. Thorne, V.F. Banzon, T. Boyer, G. Chepurin, J. H. Lawrimore, M. J. Menne, T. M. Smith, R. S. Vose, and H.-M. Zhang, 2017: Extended Reconstructed Sea Surface Temperature, version 5 (ERSSTv5): Upgrades, validations, and intercomparisons. J. Clim., 30, 8179-8205, doi: 10.1175/JCLI-D-16-0836.1. [Link]

Huangfu, J., R. Huang, W. Chen, T. Feng, and L. Wu, 2017: Interdecadal variation of tropical cyclone genesis and its relationship to the monsoon trough over the western North Pacific. Int. J. Climatol., 37, 3587-3596, doi: 10.1002/joc.4939. [Link]

Huangfu, J., R. Huang, W. Chen, and T. Feng, 2018: Causes of the active typhoon season in 2016 following a strong El Niño with a comparison to 1998. Int. J. Climatol., 38, e1107-e1118, doi: 10.1002/joc.5437. [Link]

Kim, H.-K., K.-H. Seo, S.-W. Yeh, N.-Y. Kang, and B.K. Moon, 2020: Asymmetric impact of Central Pacific ENSO on the reduction of tropical cyclone genesis frequency over the western North Pacific since the late 1990s. Clim. Dyn., 54, 661-673, doi: 10.1007/s00382019-05020-8. [Link]

Lee, C.-S., L.-R. Huang, H.-S. Shen, and S.-T. Wang, 2006: A climatology model for forecasting typhoon rainfall in Taiwan. Nat. Hazards, 37, 87-105, doi: 10.1007/ s11069-005-4658-8. [Link]

Lee, H.-T. and NOAA CDR Program, 2011: NOAA Climate Data Record (CDR) of Daily Outgoing Longwave Radiation (OLR), Version 1.2, NOAA National Climatic Data Center, doi: 10.7289/V5SJ1HH2. [Link]

Li, H., F. Xu, J. Sun, Y. Lin, and J. S. Wright, 2019: Subtropical high affects interdecadal variability of tropical cyclone genesis in the South China Sea. J. Geophys. Res., 124, 6379-6392, doi: 10.1029/2018jd029874. [Link]

Li, R. C. Y. and W. Zhou, 2014: Interdecadal Change in South China Sea Tropical Cyclone Frequency in Association with Zonal Sea Surface Temperature Gradient. J. Clim., 27, 5468-5480, doi: 10.1175/jclid-13-00744.1. [Link]

Li, R. C. Y. and W. Zhou, 2018: Revisiting the intraseasonal, interannual and interdecadal variabil- ity of tropical cyclones in the western North Pacific. Atmos. Ocean. Sci. Lett., 11, 198-208, doi: 10.1080/16742834.2018.1459460. [Link]

Li, Z., W. Yu, T. Li, V. S. N. Murty, and F. Tangang, 2013: Bimodal character of cyclone climatology in the Bay of Bengal modulated by monsoon seasonal cycle. $J$. Clim., 26, 1033-1046, doi: 10.1175/jcli-d-11-00627.1. [Link]

Liebmann, B. and C. A. Smith, 1996: Description of a complete (interpolated) outgoing longwave radiation dataset. Bull.Amer. Meteorol. Soc., 77, 1275-1277.

Lin, Y.-C., T.-J. Chang, M.-M. Lu, and H.-L. Yu, 2015: A space-time typhoon trajectories analysis in the vicinity of Taiwan. Stoch. Environ. Res. Risk Assess., 29, 18571866, doi: 10.1007/s00477-014-1001-5. [Link]

Liu, K.-S. and J. C. L. Chan, 2013: Inactive period of western North Pacific tropical cyclone activity in 1998-2011. J. Clim., 26, 2614-2630, doi: 10.1175/jclid-12-00053.1. [Link]

Lu, M.-M., P.-S. Chu, and Y.-C. Lin, 2010: Seasonal prediction of tropical cyclone activity near Taiwan using the Bayesian multivariate regression method. Weather Forecast., 25, 1780-1795, doi: 10.1175/2010waf2222408.1. [Link]

Lu, M.-M., C.-T. Lee, and B. Wang, 2013: Seasonal prediction of accumulated tropical cyclone kinetic energy around Taiwan and the sources of the predictability. Int.J. Climatol., 33, 2846-2854, doi: 10.1002/joc.3634. [Link]

Lu, M.-M., C.-T. Lee, and B. Wang, 2018: Predictability of late-season tropical cyclone accumulated kinetic energy around Taiwan 2 months ahead. Int. J. Climatol., 38, 1938-1952, doi: 10.1002/joc.5307. [Link]

Mei, W., S.-P. Xie, M. Zhao, and Y. Wang, 2015: Forced and internal variability of tropical cyclone track density in the western north Pacific. J. Clim., 28, 143-167, doi: 10.1175/jcli-d-14-00164.1. [Link]

Molinari, J. and D. Vollaro, 2013: What percentage of western north Pacific tropical cyclones form within the Monsoon Trough? Mon. Weather Rev., 141, 499-505, doi: 10.1175/mwr-d-12-00165.1. [Link]

Moon, J.-Y., B. Wang, S.-S. Lee, and K.-J. Ha, 2018: An intraseasonal genesis potential index for tropical cyclones during Northern Hemisphere summer. J. Clim., 31, 9055-9071, doi: 10.1175/jcli-d-18-0515.1. [Link]

Murakami, H. and B. Wang, 2010: Future change of North Atlantic tropical cyclone tracks: Projection by a 20-km-mesh global atmospheric model. J. Clim., 23, 2699-2721, doi: 10.1175/2010jcli3338.1. [Link]

Ritchie, E. A. and G. J. Holland, 1999: Large-scale patterns associated with tropical cyclogenesis in the western Pacific. Mon. Weather Rev., 127, 2027-2043, doi: 10.1175/1520-0493(1999)127<2027:LSPAWT>2.0. CO;2. [Link] 
Tan, P.-H., J.-Y. Tu, L. Wu, H.-S. Chen, and J.-M. Chen, 2019: Asymmetric relationships between El NiñoSouthern Oscillation and entrance tropical cyclones in the South China Sea during fall. Int. J. Climatol., 39, 1872-1888, doi: 10.1002/joc.5921. [Link]

Taylor, W. A., 2000: Change-point analysis: A powerful new tool for detecting changes. Change-Point Analyzer, Taylor Enterprises, Libertyville, Illinois, 1-19. Available at http://www.variation.com/cpa/tech/ changepoint.html.

Tu, J.-Y., C. Chou, and P.-S. Chu, 2009: The abrupt shift of typhoon activity in the vicinity of Taiwan and its association with western North Pacific-East Asian climate change. J. Clim., 22, 3617-3628, doi: 10.1175/2009jcli2411.1. [Link]

Tu, J.-Y., J.-M. Chen, L. Wu, and C.-Z. Chi, 2020: Interdecadal and inter-annual variability of meridional tropical cyclone activity during September-October in the northwestern North Pacific after 1998. Int. J. Climatol., 40, 1686-1702, doi: 10.1002/joc.6295. [Link]

Wang, B. and J.-Y. Moon, 2017: An anomalous genesis potential index for MJO modulation of tropical cyclones. J. Clim., 30, 4021-4035, doi: 10.1175/jcli-d-16-0749.1 . [Link]

Yoshida, R. and H. Ishikawa, 2013: Environmental factors contributing to tropical cyclone genesis over the west- ern North Pacific. Mon. Weather Rev., 141, 451-467, doi: 10.1175/MWR-D-11-00309.1. [Link]

Yu, J.-Y. and P.-G. Chiu, 2012: Contrasting various metrics for measuring tropical cyclone activity. Terr. Atmos. Ocean. Sci., 23, 303-316, doi: 10.3319/ TAO.2011.11.23.01(A). [Link]

Yu, J.-Y., C. Chou, and P.-G. Chiu, 2009: A revised accumulated cyclone energy index. Geophys. Res. Lett., 36, L14710, doi: 10.1029/2009GL039254. [Link]

Zhan, R., Y. Wang, and J.Zhao, 2019: Contributions of SST Anomalies in the Indo-Pacific Ocean to the Interannual Variability of Tropical Cyclone Genesis Frequency over the Western North Pacific. J. Clim., 32, 33573372, doi: 10.1175/jcli-d-18-0439.1. [Link]

Zhang, W., G. A. Vecchi, H. Murakami, G. Villarini, T. L. Delworth, X. Yang, and L. Jia, 2018: Dominant Role of Atlantic Multidecadal Oscillation in the Recent Decadal Changes in Western North Pacific Tropical Cyclone Activity. Geophys. Res. Lett., 45, 354-362, doi: 10.1002/2017gl076397. [Link]

Zhao, J., R. Zhan, Y. Wang, and H. Xu, 2018: Contribution of the Interdecadal Pacific Oscillation to the Recent Abrupt Decrease in Tropical Cyclone Genesis Frequency over the Western North Pacific since 1998. J. Clim., 31, 8211-8224, doi: 10.1175/jcli-d-18-0202.1. [Link] 